\title{
A STUDY ON THE IMPACT OF YOGA ON DAILY YOGA PRACTITIONERS
}

\author{
Mr Naranath Pandey *
}

\begin{abstract}
This study identifies the reasons for practicing and the impact of yoga in yoga practitioners among different yoga centers in Kawasoti Nawalpur. Yoga is a part of mainstream culture today, with major medical centers, community healthcare centers, and neighborhood yoga studios offering yoga as a mind-body practice to support health and healing. The significance of this research is to study the physical and mental impacts of yoga on daily yoga practitioners at yoga centers in Kawasoti Nawalpur. For this, the researcher went to various yoga centers and met the people who practice daily yoga, and inquired about the causes and impact of yoga. This study shows that the main reasons for practicing yoga among yoga practitioners were; backache, joint pain, or muscular pain (33.33 percent) and abdominal problems including gastritis and uterine problem (38.88 percent). Yoga practitioners experienced the positive effects and achievements of yoga are; backache, joint pain or muscular pain (29.16 percent) improve, and abdominal problem including gastritis and uterine problem (50.00 percent) improve. So, after identifying the positive impacts of yoga, the researcher suggests that more emphasis or public awareness can be given to yoga practice for minimizing chronic health problems. The findings will help the individual, teachers, scholars, career, and counseling centers.
\end{abstract}

Key words: Yoga, asanas, pranayama, poses, meditation.

\section{Introduction}

Yoga helps to increase peace of mind, consciousness, and soul. Improves physical, mental, social, and spiritual harmony. Maintains the glucose regulation in our body and fight cancer-like chronic diseases. Yoga originated and gave us valuable, practical instructions for the body, breath, concentration, relaxation, and meditation. It improves physical fitness, cardiovascular endurance, postures, increases the intake of oxygen, and enhances the functioning of the different systems of our body such as the circulatory, musculoskeletal functioning, and pain, respiratory, digestive, endocrine, reproductive, and excretory system.

Most recent literature based on the impact of yoga and meditation on human health, particularly on psychological disorders (e.g., mental stress, anxiety, etc.), endocrine disorders (e.g., thyroidism, gigantism, etc.), metabolic disorders (e.g., diabetes, hyperlipidemia, cancers, etc.) and neurological disorders (e.g., Alzheimer's disease, etc.) were thoroughly reviewed.

Yogic asanas make the body physically healthy, the mind focused, and bring stress under control thereby striking balance between body, mind,

\footnotetext{
* Mr. Pandey is Teaching Assistant of Madhyabindu Multiple Campus, and Ph.D. Scholar of Nepal Sanskrit University, Research Center.
} 


\section{The Journal of Madhyabindu Multiple Campus, Vol. 6, No. 1, 2021}

and soul which enables a cordial relationship with family, friends, and in the workplacehence the quality oflife too(Mary,2016).

Yoga is "lessons in the science of deep breathing, concentration, meditation and self-control" (Roy,1910, p.114). As the Swiss-born Physician, Paracelsus, very correctly said, "Health isn't everything, but without health everything is nothing". To preserve and restore health there are physical exercises (Asanas), breath exercises (Pranayama), and relaxation techniques. Hence, practicing yoga in day-to-day life helps to maintain a healthy relationship between the mind and the body (Sovik, \& Bhavanani, 2016, p.17). There is an interrelationship between the mind and the body "when the body is physically healthy, the mind is focused and stress is under control" (Yadav, 2015. p.7). A decade later, in the late1930 s, the postural practice started to become associated with yoga, both as physical culture magazines announced the new arrival of yogic postures and as established teachers of yoga shifted their teachings from mental exercises and relaxation to include such asanas as bow and plow (Evans, 1940. pp.30-59)

In a modern context, yoga has been defined as "a systematic practice and implementation of mind and body in the living process of human beings to keep harmony within the self, within society, and with nature (Galena, 1994. p.14)".

Yoga is a great way to work on our flexibility and strength. Just about everyone can do it. The health benefits of yoga are: Yoga for flexibility, strike a pose for strength, better posture from yoga, breathing benefits, less stress and more calm, good for heart, etc. (https://www.webmd.com/balance/guide/thehealth-benefits-of-yoga)

In the initial stages of yoga study, most practitioners focus on postures (asana), voluntary regulation of the breath (pranayama), and relaxation skills (pratyahara). Integrated with the contemplation of the Yamas and niyamas, these form the foundation for the development of effective practice(Sharma, 2014. pp.59-67).
However, it is helpful to broaden the focus here to provide a philosophical context and illustrate how yoga techniques expand into daily life. Yoga is indeed a way of life, and an experiential investigation into human nature (Bhavanani, 2003).

The objectives of this study are to explore the reasons for yoga practice among yoga practitioners in Kawasoti yoga centers, to find out the popular yoga poses, and to understand the effects and achievements of yoga practice among them.

\section{Methods and Procedures}

This study was based on a survey design. The researcher decided to focus on study in yoga centers at the yoga practitioners at daily yoga centers of Kawasoti area Nawalpur. In a study conducted in Kawasoti, a total of 72 respondents were interviewed at five yoga centers. 15 people at Rammandir yoga center, 22 at Siddhartha yoga center, 15 at Danda yoga center, 12 at Pragatinagar yoga center, and 8 at Gyanodaya yoga center.

The information was collected from primary data. The primary information was collected using the interview schedule and directly from the yoga practitioner at the yoga center. The yoga practitioner present at the daily yoga center was selected as the respondent. The research was based on a theoretical or mostly qualitative model. In this regard, secondary information was collected from various libraries, and some on-line journals, thesis, books, magazines were also reviewed in this direction.

The purpose of the research is to study the physical and mental impacts of yoga, on yoga practitioners at yoga centers in Kawasoti Nawalpur. For that reason, the researcher himself is a yoga instructor and a daily yoga practitioner. The practice of yoga is the only alternative solution to the deadly and non-communicable diseases in the world. For this, the researcher has become more willing to go to the 
daily yoga centers and directly understand the condition and impact of the yoga practitioners.

\section{Result and Discussion}

This research was being done at various yoga centers in Kawasoti Nawalpur. The yoga practitioners who come to the yoga centers organized by Patanjali Yoga Committee Nawalpur said that they will solve their problems through various asanas, exercises, and pranayama and those who do not have any problem will engage in yoga practice to stay healthy and fit. There are many different styles of yoga being practiced today. While almost all styles are based on a series of postures. Consult with a certified teacher to determine the best style of yoga for our physical fitness and overall health goals. The results of the study are presented as follows:

\section{Age and sex of respondents}

Table number 1 shows that the total number of respondents was 72 . The majority of respondents belong to the age group of $20-40$ years i.e. (30 people) 41.66 percent. About 15.27 percent of respondents were up to 19 years. Similarly, there was 29.17 percent of respondents age 41-60 years. The data revealed 11.12 percent of respondents have aged $61-70$ years and above 70 years of age were 2.78 percent.

Table 1

Distribution of respondents by age and sex

\begin{tabular}{|l|l|l|l|l|l|l|}
\hline Variables & \multicolumn{2}{l|}{ Frequency } & \multicolumn{2}{l|}{ Percentage } \\
\hline Age/sex & Male & Female & Total & Male & Female & Total \\
\hline Up to 19 & 5 & 6 & 11 & 6.94 & 8.33 & 15.27 \\
\hline $20-40$ & 14 & 16 & 30 & 19.44 & 22.22 & 41.66 \\
\hline $41-60$ & 11 & 10 & 21 & 15.28 & 13.89 & 29.17 \\
\hline $61-70$ & 5 & 3 & 8 & 6.95 & 4.17 & 11.12 \\
\hline $70+$ & 2 & 0 & 2 & 2.78 & 0 & 2.78 \\
\hline Total & $\mathbf{3 7}$ & $\mathbf{3 5}$ & $\mathbf{7 2}$ & $\mathbf{5 1 . 3 9}$ & $\mathbf{4 8 . 6 1}$ & $\mathbf{1 0 0}$ \\
\hline
\end{tabular}

Source: Field survey, 2020

Table 1 demonstrate that the majority of yoga practitioners (41.66 percent) are 20-40 years old. Yoga practitioners up to 19 years were 15.27 percent. But the old aged $61-70$ years respondents (11.12 percent) and over the age of 70 has been found ( 2.78 percent) as respondents.

Similarly, table number 1 shows that the male respondents were 37 people (51.39 percent) and females were 35 (48.61 percent).

As shown in table number one, people under the age of 19 are not enthusiastic about yoga, but studies have shown that the reason why a person does yoga is only that he is suffering from some disease or condition. That's why older people are more interested in yoga because they have some physical and mental problems. Similarly, people up to the age of 19 seem to be engaging in yoga practice nowadays. Incorporating yoga and lifestyle issues into the school curriculum and increasing awareness, they also seem to be gradually joining yoga practice. But in the minds of many children, there is a mentality that this is a practice by people who are physically ill.

\section{Yoga practitioner's reasons to practice yoga}

Yoga practitioners seem to be more conscious now. They seem to understand that yoga practice is an important way to get rid of the compulsion to take medicine for the rest of their lives and to change their lifestyle to stay healthy. Studies 
show that many people nowadays practice yoga because they believe that yoga can help them to get rid of the need to take medicine for life. But there is still no change in the reality that people should do yoga without getting any suffering.

In this study, the first part of the questionnaire indicates the reason for yoga practice is headache or migraine and anxiety or other mental problem shows 23.61 percent (17 people), backache and joint pain and obesity shows same 33.33 percent (24 people) out of 72 respondents. Whereas the highest cause of yoga was hypertension or heart diseases 47.22 percent (34 people) and abdominal problems ( 38.88 percent). It was observed that sleep apnea and lazy, ill and unhealthy life was another cause of yoga practice was same (20.83 percent). The reason for yoga practice due to piles and constipation was 16.66 percent. The other causes of yoga practice were diabetes mellitus ( 25 percent) and the reason for involvement in yoga was sinusitis, allergy, or asthma ( 37.5 percent). Only three respondents ( 4.16 percent) were found who were suffering from thyroid or hypothyroidism. This type of result shows that multiple problems are presented in yoga practitioners. This is shown in table number two below:

Table 2

Yoga practitioner's reasons to practice yoga

\begin{tabular}{|c|c|c|c|c|c|}
\hline \multirow[t]{2}{*}{ Reasons } & \multicolumn{5}{|c|}{ Frequency (respondent number) } \\
\hline & Mild & Moderate & Severe & Total & $\begin{array}{l}\text { Percentage } \\
\text { (out of } 72 \\
\text { respondents) }\end{array}$ \\
\hline Hypertension or heart diseases & 12 & 10 & 13 & 34 & 47.22 \\
\hline $\begin{array}{l}\text { Abdominal problems, anorexia, } \\
\text { indigestion, gastritis, etc }\end{array}$ & 5 & 15 & 8 & 28 & 38.88 \\
\hline Sinusitis, allergy, and asthma & 12 & 7 & 8 & 27 & 37.5 \\
\hline $\begin{array}{l}\text { Muscular pain, neck pain, joint } \\
\text { or back pain }\end{array}$ & 10 & 5 & 9 & 24 & 33.33 \\
\hline Obesity & 11 & 8 & 5 & 24 & 33.33 \\
\hline Diabetes mellitus & 4 & 3 & 6 & 13 & 25.0 \\
\hline $\begin{array}{l}\text { Anxiety, deconcentrating, fear, } \\
\text { and stress }\end{array}$ & 10 & 0 & 7 & 17 & 23.61 \\
\hline $\begin{array}{l}\text { Anxiety, deconcentrating, fear, } \\
\text { and stress }\end{array}$ & 10 & 0 & 7 & 17 & 23.61 \\
\hline Headache or migraine & 8 & 3 & 6 & 17 & 23.61 \\
\hline Unhealthy, lazy, and ill life & 7 & 3 & 5 & 15 & 20.83 \\
\hline Piles and constipation & 3 & 4 & 5 & 12 & 16.66 \\
\hline $\begin{array}{l}\text { Thyroid or another throat } \\
\text { problem }\end{array}$ & 0 & 0 & 3 & 3 & 4.16 \\
\hline
\end{tabular}

Source: Field survey, 2020 
The result of this study shows that it has been found that many people are connected to yoga for one reason or another. Yoga practitioners have said that they are especially involved in yoga due to high blood pressure, abdominal problems, diabetes, joint pain, obesity, etc.

The interview was conducted with the respondent (interviewee 1), aged 60 years male yoga practitioner asserted that he used to take a variety of medicines. He had severe back pain, muscle pain, high blood sugar, high blood pressure, and other heart problems. That is why he is engaged in yoga practice.

Similarly, interviewee 2 , aged 36 years female said she had obesity, various stomach ailments, and the most common problem was a cyst in her uterus. Due to which she had to have abdominal pain and also her period was irregular.

Another (interviewee 3), aged 37-year-old male yoga practitioner said that- he used to practice yoga to treat back pain and joint pain, gastritis and stomach problems, problems of piles and constipation, high blood pressure, and an unhealthy lifestyle.

\section{The main yoga exercises}

In this study, out of the various asanas and pranayama performed by the yoga practitioners, the following are some of the most preferred yoga asanas and pranayama being satisfied with respondents with daily practice. Here are a few basic yoga asanas are performed by the respondents in this study: Pose of sun salutations (Surya-Namaskar), Yogging jugging, Danda, the exercise of limbs, etc., and other pranayamas like bhastrika, kapalvati, and anulom bilom.

Yoga does more than burn calories and tone muscles. It's a total mind-body workout that combines strengthening and stretching poses with deep breathing and meditation or relaxation. There are more than 100 different forms of yoga. Some are fast-paced and intense. Others are gentle and relaxing. Examples of different yoga forms include Hatha, Vinyasa, Ashtanga, Bikram, Iyengar, Warm-up poses (Upper body twist, forward/backward bend, side bends, upper body rotation, shoulder rotation, wrists rotation, head rotation, swinging while standing pose), etc.

(https://www.webmd.com/fitness-exercise/a-z/yogaworkouts)

Although yoga exercise can be different, yoga practitioners preferred and practicing yoga exercises are shown in table three below:

Table 3

The main yoga exercises preferred by yoga practitioners

\begin{tabular}{|l|l|l|l|l|l|l|l|l|}
\hline \multirow{2}{*}{ Yoga exercises } & \multicolumn{7}{|c|}{ Frequency } \\
\cline { 2 - 10 } & Dislike & \multicolumn{2}{|c|}{ Good } & \multicolumn{2}{l|}{ Very good } & \multicolumn{2}{l|}{ Excellent } \\
\cline { 2 - 10 } & No & $\mathbf{\%}$ & No & \% & No & \% & No & $\%$ \\
\hline $\begin{array}{l}\text { Bhastrika, Kapalbhati, } \\
\text { Anulom bilom pranayam }\end{array}$ & 0 & 0 & 1 & 4.54 & 2 & 9.09 & 19 & 86.36 \\
\hline Suryanamaskar & 1 & 4.54 & 1 & 4.54 & 1 & 4.54 & 19 & 86.36 \\
\hline Exercise of limbs & 0 & 0 & 2 & 9.09 & 3 & 13.63 & 17 & 77.27 \\
\hline $\begin{array}{l}\text { Yogging, Jogging and } \\
\text { Danda }\end{array}$ & 1 & 4.54 & 2 & 9.09 & 3 & 13.63 & 16 & 72.72 \\
\hline $\begin{array}{l}\text { Balasana, Shavasana and } \\
\text { Hasyasana }\end{array}$ & 3 & 13.63 & 2 & 9.09 & 2 & 9.09 & 15 & 68.18 \\
\hline $\begin{array}{l}\text { Ujjayi, Bhramari, Udgith, } \\
\text { and Pranav dhyan }\end{array}$ & 0 & 0 & 4 & 18.18 & 4 & 18.18 & 14 & 63.63 \\
\hline
\end{tabular}


72 The Journal of Madhyabindu Multiple Campus, Vol. 6, No. 1, 2021

\begin{tabular}{|l|l|l|l|l|l|l|l|l|}
\hline $\begin{array}{l}\text { Padbrittasana and } \\
\text { dwichakrikasana }\end{array}$ & 1 & 4.54 & 5 & 27.72 & 3 & 13.63 & 13 & 59.09 \\
\hline Mandukasana & 0 & 0 & 7 & 31.81 & 3 & 13.63 & 12 & 54.54 \\
\hline Markatasana & 2 & 9.09 & 4 & 18.18 & 5 & 27.72 & 11 & 50.00 \\
\hline Pawan mukthasana & 2 & 9.09 & 5 & 27.72 & 4 & 18.18 & 11 & 50.50 \\
\hline Makarasana & 2 & 9.09 & 6 & 27.27 & 5 & 22.72 & 9 & 40.90 \\
\hline Shalavasana & 3 & 13.63 & 4 & 18.18 & 6 & 27.27 & 9 & 40.90 \\
\hline
\end{tabular}

Source: Field survey, 2020

A result of this study in table number three shows that the main popular yoga exercises among daily yoga practitioners are; Pranayama and Surya namaskar both (excellent: 86.36 percent), whereas other highest levels of popular yoga exercise are an exercise of limbs (excellent: 77.27 percent), Yogging, Jugging and Danda is 72.72 percent. It is observed that like Balasana, Shavasana and Hasyasana asana are another popular yoga (excellent: 68.18 percent), the other popular yoga is: Ujjayi, Bhramari, Udgidh and Pranavdhyan (excellent: 63.63 percent), Padbrittasana and Dwichakrikasana is 59.09 percent, Mandukasana is 54.54 percent, Markatasana and Pawan muktasana are 50.00 percent, and Makarasana and Shalavasana are 40.90 percent, etc.

Most of practitioners were less like or dislike the exercises are Salavasana and Balasana, Hhasyasana 13.63 percent, Makarasana, Markatasana and Pawanmuktasana 9.09 percent and Yogging, Jogging, Danda, Surya namaskar, Padbrittasana and Dwichakrikasana are same 4.54 percent.

Those who say good in daily yoga practice are Mandukasana 31.81 percent, Makarasana, Pawanmuktasana, Padbrittasana and Dwichakrikasana are 27.27 percent, Markatasana, Shalavasana and Ujjai, Bhramari, Udgith and Pranavdhyan are 18.18 percent, Yogging, Jugging, Danda, Balasana, Shavasana, Hasyasana and exercise of limbs are 9.09 percent and Bhastrika, Kapalvati, Anulombilom pranayama and Suryanamaskar are 4.54 percent.

Similarly, those who say very good yoga practice are Shalavasana and Markatasana 27.72 percent, Makarasana 22.72 percent, Pawanmuktasana and Ujjai, Bhramari, Udgith and Pranavdhyan are 18.18 percent, Yogging, Jugging and Danda, Mandukasana, Padbrittasana and Dwichakrikasana and exercise of limbs are 13.63 percent, Bhastrika, Kapalbhati, Anulombilom pranayama and Balasana, Shavasana and Hasyasana are 9.09 percent and Suryanamaskar is 4.54 percent.

\section{The effects of practicing yoga}

It was found that the daily yoga classes conducted at various yoga centers in Kawasoti Nawalpur were conducted by Patanjali Yoga Committee. Many effective results have been seen in the yoga practitioners who have conducted daily yoga classes by various trained yoga instructors under that committee.

In this study, a cent percent of the respondents answered that they feel the effects and achievements of yoga in their life by regular yoga practice. The result in table number four shows that those who had a thyroid or another throat problem (three respondents) and those who had anxiety, concentration problems, fear, and stress (17 respondents) were said to have recovered cent percent from yoga practice. Whereas 70.59 percent (out of 17 people) said very good improvement of headache or migraine and 29.41 percent (five-person) said a mild improvement in the same case.

Similarly, out of a total of 24 obese people, 13 persons (54.16 percent) with a very good improvement of their problem by yoga practice and 11 persons (45.83 percent) with mild improvement. Similarly, 10 out of 15 
respondents who did not get sleep had very good improvement (66.66 percent) and five ( 33.33 percent) had mild improvement by yoga practice. Out of 34 persons; 22 persons ( 64.70 percent) had very good improvement of hypertension or heart diseases, 12 persons ( 35.29 percent) had mild improvement by yoga practice. People who were unhealthy, lazy, and ill life; out of 15 persons seven ( 46.67 percent) had very good improvement and 8 (53.33 percent) respondents had moderate improvement by yoga practice.

Likewise, out of 24 respondents who had muscular pain, neck pain, joint or back pain; seven persons (29.16 percent) with very good improvement, five persons (20.83 percent) had moderate improvement and 12 (50.00 percent) had mild improvement. Out of 27 respondents who had sinusitis, allergy, and asthma 10 persons (37.03 percent) had very good improvement and five people (18.52 percent) have moderate improvement, and the rest 12 person (44.44 percent) have mild improvement by yoga practice. Out of 13 respondents who had diabetes mellitus; six persons (46.15 percent) had very good improvement and seven persons ( 53.84 percent) had mild improvement. Out of 28 respondents who have abdominal problems, anorexia, indigestion, and gastritis; 14 persons $(50.00$ percent) had very good improvement, six persons (21.42 percent) had moderate improvement and eight persons (28.57 percent) had mild improvement.

Table 4

Improvements found yoga practitioners by practicing daily yoga

\begin{tabular}{|c|c|c|c|c|c|c|c|c|c|}
\hline \multirow[t]{3}{*}{ Variables } & \multirow{3}{*}{$\begin{array}{l}\text { Problems } \\
\text { in }\end{array}$} & \multicolumn{8}{|c|}{ Frequency } \\
\hline & & \multicolumn{2}{|c|}{ No improvement } & \multicolumn{2}{|c|}{$\begin{array}{l}\text { Mild } \\
\text { improvement }\end{array}$} & \multicolumn{2}{|c|}{$\begin{array}{l}\text { Moderate } \\
\text { improvement }\end{array}$} & \multicolumn{2}{|c|}{$\begin{array}{l}\text { Very good } \\
\text { improvement }\end{array}$} \\
\hline & & No. & $\%$ & No. & $\%$ & No. & $\%$ & No. & $\%$ \\
\hline $\begin{array}{l}\text { Thyroid or another throat } \\
\text { problem }\end{array}$ & 3 & 0 & 0 & 0 & 0 & 0 & 0 & 3 & 100 \\
\hline $\begin{array}{l}\text { Anxiety, deconcentrating, } \\
\text { fear, and stress }\end{array}$ & 17 & 0 & 0 & 0 & 0 & 0 & 0 & 17 & 100 \\
\hline Headache or migraine & 17 & 0 & 0 & 5 & 29.41 & 0 & 0 & 12 & 70.59 \\
\hline Sleep apnea & 15 & 0 & 0 & 5 & 33.33 & 0 & 0 & 10 & 66.66 \\
\hline $\begin{array}{l}\text { Hypertension or heart } \\
\text { diseases }\end{array}$ & 34 & 0 & 0 & 12 & 35.29 & 0 & 0 & 22 & 64.70 \\
\hline Obesity & 24 & 0 & 0 & 11 & 45.83 & 0 & 0 & 13 & 54.16 \\
\hline $\begin{array}{l}\text { Abdominal problems, } \\
\text { anorexia, indigestion, } \\
\text { gastritis, etc. }\end{array}$ & 28 & 0 & 0 & 8 & 28.57 & 6 & 21.42 & 14 & 50.00 \\
\hline Unhealthy, lazy, and ill life & 15 & 0 & 0 & 0 & 0 & 8 & 53.33 & 7 & 46.67 \\
\hline Diabetes mellitus & 13 & 0 & 0 & 7 & 53.84 & 0 & 0 & 6 & 46.15 \\
\hline $\begin{array}{l}\text { Sinusitis, allergy, and } \\
\text { asthma }\end{array}$ & 27 & 0 & 0 & 12 & 44.44 & 5 & 18.52 & 10 & 37.03 \\
\hline Piles and constipation & 12 & 0 & 0 & 6 & 50.00 & 2 & 16.67 & 4 & 33.33 \\
\hline $\begin{array}{l}\text { Muscular pain, neck pain, } \\
\text { joint or back pain }\end{array}$ & 24 & 0 & 0 & 12 & 50.00 & 5 & 20.83 & 7 & 29.16 \\
\hline
\end{tabular}

Source: Field survey, 2020

This study shows that daily yoga practitioners feel yoga practice has a very positive effect on health. According to a 47 years old male respondent with high blood pressure and diabetes, he used to take a variety of medications at first, but since he started practicing yoga, he has been gradually reducing his dosage and has stopped taking all medications. What this means is that yoga practice is the gift of the present age.

According to another 48 years old male respondent, he was obese (about $95 \mathrm{~kg}$ ). He had many 


\section{The Journal of Madhyabindu Multiple Campus, Vol. 6, No. 1, 2021}

health problems due to obesity. At that point, he started practicing yoga. When he practiced yoga regularly, he lost $12 \mathrm{~kg}$ weight in four months and his other physical problems were cured. What can be understood from this is that regular yoga practice can reduce obesity and its problems.

Similarly, in another 36 years, the old female respondent had various physical problems. Her main problems were irregular menstruation, lower abdominal pain, loss of appetite, inability to work, and weakness. She had a small lump in her uterus when she was examined and there were other problems in her uterus which caused her menstrual irregularities and abdominal pain. As she began to practice yoga, her physical problems gradually subsided, and she began to reduce the amount of medication she took. The size of the lump in her uterus is also decreasing and she has to have an operation to remove the uterus, but now her uterus is getting healthy and she is physically and mentally healthy. Her period is regular, she is completely satisfied with yoga practice. What can be understood from this incident is that yoga practice is an important practice which, if continued regularly, will solve our innumerable physical problems.

\section{Conclusion}

Yoga is the only way to solve many problems for a physically and mentally satisfying human life. This study also shows that many lifestyle diseases or non-communicable diseases can be solved through yoga. Regular practice will strengthen the muscles of our arms, back, legs, and other parts. Although yoga will give us a full-body workout, it won't put any impact on our joints.

Yoga can help cure insomnia, as regular yoga practice leads to better and deeper sleep. Yoga can help to fight fatigue and maintain energy. Yoga is an effective treatment for a variety of autoimmune diseases because it can reduce the symptoms of diseases often cause, such as stiffness, malaise, fatigue, and weakness. This recent study shows that there is a big problem of non-communicable diseases in the community and the only way to solve these problems is for people to do physical labor. The public interest in yoga and meditation is increasing day by day due to their beneficial effects on mental and physical health.

The result indicates that daily yoga practitioners of Kawasoti Nawlpur feel the health problems are; back pain, muscle pain, neck pain and joint pain (33.33 percent), gastritis, abdominal pain, indigestion, anorexia (38.38 percent) piles or constipation (16.66 percent), headache, and migraine (23.61 percent), etc.

The yoga impact on yoga practitioners is: Problems with thyroid or other throat problems and anxiety, deconcentrating, fear and stress are cured cent percent, headache or migraine problems are cured 70.59 percent. Of those with obesity, 54.16 percent found significant improvement, sleep apnea 66.66 percent found improvement, muscle, joint, neck, and back pain are cured 29.16 percent, etc. This study shows that yoga practice is the main treatment for all physical and mental ailments.

The result indicates that yoga practitioners feel the best yoga practice are Pranayam and Suryanamaskar same percent (86.36 percent). Likewise, Yogging, jugging, and danda (72.72 percent) and exercise of limbs (77.27 percent), etc. are also feeling the best yoga.

The researcher would like to suggest that to solve the problems related to the existing lifestyle in the community, to solve many problems such as obesity, high blood pressure, diabetes, thyroid, to get mental satisfaction, to eliminate anxiety, to solve the problem of insomnia, etc. it is necessary to practice yoga regularly to solve these various problems. 


\section{References}

Bhavanani, A.B. (2003). Effect of yoga training on the handgrip, respiratory pressures, and pulmonary function. Indian J Physio 1 Pharmocol 47: 387-392. 27.

Crishop, E.D. (1945). "Yoga an Aid to Health". Health Culture 52 (11): 28-29, 40-43.

Evans, W. (1940). "Yoga Comes to the Western World”. Physical Culture May, 30-31, 5759.

Galena, (1994). Integrating yoga therapy into rehabilitation. p.14. Copyright 1999, Embog publication.

Groessl, E.J., Chopra D. \& Mills P.J. (2015). An Overview of Yoga Research for Health and Well-Being.

Mary, G. (2016). Role of yoga in Salutogenesis.

Roy, B.K. (1910). "Hindoo Missionaries in America.” New Thought Magazine Vol. 19, No. 3 (March): 109-115.

Sharma, M. (2014). Journal of Evidence-Based Complementary \& Alternative Medicine, Vol. 19 (1) pp.59-67.

Sovik, R. \& Bhavanani, A. (2016). History, philosophy, and practice of yoga, p.17.

Hartfiel, N. Havenhand,J., Khalsa, S.B., Clarke, G.\& Krayer, A. (2011). The effectiveness of yoga for the improvement of well-being and resilience to stress in the workplace. Scand J Work Environ Health.Vol.37(1): pp.70-76.

Yadav, S. K. (2015). Importance of yoga in daily life. DOI: 10.13140/RG.2.1.4538.3842

http://nrs.harvard.edu/urn-3:HUL.InstRepos:10436227

http://www.ncbi.nlm.nih.gov/pubmed/

https://www.webmd.com/balance/guide/the-health-benefits-of-yoga

https://www.webmd.com/fitness-exercise/a-z/yoga-workouts

http://www.sagepub.com/DOI: 10.1177/2156587213503344 